\title{
György Lukács, la orientación sentimental o el concepto
}

\section{György Lukács, the sentimental orientation or concept}

\author{
Carlos Surghi \\ Universidad Nacional de Córdoba. Argentina. \\ carlossurghi@yahoo.com.ar
}

\section{Resumen}

El presente trabajo es un estudio teórico de la relación existente entre experiencia y teoría, reflexión y escritura en los textos de György Lukács, particularmente en su Diario 19101911, que junto con el ya clásico estudio El alma y las formas, definen un procedimiento de expresión propio de la modernidad: la escritura como experiencia del yo, y el ensayo como forma de la crítica. De este modo, en el espacio que ambos textos configuran, nuestro trabajo busca evidenciar la relación existente entre escritura de la intimidad (el diario) y reflexión crítica (el ensayo), lo cual nos lleva a pensar que una y otra dimensión delimitan procedimientos discursivos particulares para pensar la singularidad del fenómeno estético desde la experiencia del yo.

Palabras clave: intimidad, escritura, yo, experiencia, forma.

\section{Abstract}

The present work is a theoretical study of the relationship between experience and theory, reflection and writing texts György Lukács, particularly in his Diary 1910-1911, together with the classic study The soul and the forms, defined a method of self expression of modernity: writing as I experience, and testing as a form of review. Thus, in the space that both texts set, our work seeks to show the relationship between writing of privacy (daily) and critical reflection (the trial), which leads us to believe that one dimension delimiting discursive procedures individual to think the uniqueness of the aesthetic phenomenon from the experience of self.

Keywords: Privacy, Writing, I, Experience, Form. 


\section{El yo es aquel que escribe}

Pensar la escritura del yo en sus diversas formas es pensar de algún modo la forma en que la invención moderna de la subjetividad ha ido evolucionando a lo largo del tiempo ${ }^{1}$. Pensemos que a simple vista la designación escrituras del yo es un tanto general, imprecisa y vaga. ¿De qué yo trata el que escribe? ¿No es toda escritura de su incumbencia? ¿No es el yo la ilusión de toda forma por realizarse? En realidad la vaguedad misma del término es lo que le da su alcance metodológico; en algún punto todo estudio sobre este tema se dice a sí mismo: mejor ser inciertos pero inspirados, antes que precisos y aburridos. El diario, las cartas, los registros autobiográficos -acaso lugares o formas pertinentes al yo- todo parece ser hoy en día material en desuso que puede reutilizarse al momento de pensar lo que no puede ser pensado: la intimidad ${ }^{2}$. Desde ya que la existencia de un yo remite a la presencia de la intimidad en el espacio del discurso. Igualmente la simple presunción de intimidad supone que sólo el yo, como entidad y lugar de enunciación, puede pensarla y realizarla en tanto que verdadera problemática del discurso. Ahora bien, tal vez por eso, en el límite de la forma de lo escrito está esa intimidad que se nombra como última forma pero que nunca llega a definirse. ¿Deberíamos entonces decir que toda forma es íntima y por eso mismo no hay nada que la reduzca? Si es así deberíamos acordar que hablar del yo es hablar de lo íntimo; y por lo tanto lo íntimo nos supone algo imposible de reducir, algo que como sustancia emana en todas direcciones, y ni bien queremos encontrarle una orientación fracasamos, se transforma en el fantasma de toda escritura.

¿Pero en qué sentido el yo se hace presente en el mundo cuando lo íntimo busca una forma escrita? ¿El yo es una forma de acuerdo con el mundo? ¿O en todo caso el yo es la negación rotunda del mundo como lo íntimo es la negación de cualquier forma? Nos animaríamos a decir que el yo aparece justamente como negación, como algo que vacila y jamás se cristaliza, pues existe una extraña paradoja respecto a lo que el yo significa para la cultura centroeuropea. Desde la ilustración y su llamado a la mayoría de edad, pasando por la reacción romántica, hasta llegar a lo que podríamos llamar el desencanto de Viena, el yo ha sido reducido, ampliado, negado, elogiado, cantado por la poesía, sepultado por la filosofía, analizado por el ojo terapéutico y

1 Para un acercamiento a esta problemática sugerimos consultar el dossier "Escrituras del Yo" de la revista Badebec (2011); como así también el texto de Daniel Link "La imaginación intimista" (2007). Sin embargo para un estado actual de las investigaciones sobre este tema, se hace necesario mencionar una genealogía de textos teóricometodológicos que subyace por detrás de los textos citados, los cuales desde ya forman parte de lo que podríamos denominar "la constelación intimista", como por caso lo son Las fuentes del yo (2006) de Charles Taylor, El espacio biográfico. Dilemas de la subjetividad contemporánea (2002) de Leonor Arfuch, El espacio autobiográfico (1991), En la era de la intimidad (2007) de Nora Catelli, La intimidad como espectáculo (2008) de Paula Sibilia, o el ya clásico How lives become stories. Makin Selves (1999) de Paul Eakin.

2 Entendemos y desplegamos este término siguiendo lo expuesto por Alberto Giordano al señalar que la misma puede pensarse como "una dimensión irrepresentable de la subjetividad, una reserva de indeterminación que escapa a la dinámica simple en la que lo privado y lo público se oponen para poder complementarse" (cit. en $E l$ giro autobiográfico de la literatura argentina actual 52). 
rehabilitado por la esperanza política de una utopía social. A grandes rasgos el yo ha sido el espectro de la cultura de la modernidad; pues sus traumas han tenido que orientarse en función de una teoría del comportamiento social, y esa misma orientación, ha significado el fin de toda experiencia, la desacralización de lo cotidiano, la falta absoluta de comprensión respecto a lo real. Pensemos entonces una formula contradictoria para el yo, tan sólo para poder nombrarlo, otra alternativa no nos queda pues ni bien éste habla, tartamudea, ni bien canta, hace silencio; y en su palabra esperanzada está al mismo tiempo el desencanto. Afirmemos entonce, al menos para nosotros y en el alcance de este trabajo, que el yo es la pura esperanza del desencanto.

\section{La juventud como forma}

Desencanto no es una palabra caprichosa; desencanto es la palabra que mejor le cabe al yo, tal vez es la única que repite insistentemente: el yo es otro; el yo es profundamente anti-spinoziano; frente al yo la esperanza del desencanto tiene por fin desnudar y evidenciar quién verdaderamente se es y se ignora. En el caso de Lukács el desencanto ha sido aquello ante lo cual había que escribir; el desencanto con el presente llevó a transformar la escritura en reacción, crítica, interpelación metodológica. Sólo en tanto que hay desencanto existe el yo que escribe; por lo tanto esa figura difusa del joven intelectual húngaro que eclipsa la atención de Thomas Mann, o que fascina a Theodor Adorno, resulta ser la figura de un joven disconforme, atormentado por el deseo de lo auténtico y por demás atento a encontrar una explicación al presente sin perder de vista el pasado de una tradición que sentía como propia ${ }^{3}$. ¿Pero qué había que escribir para combatir el desencanto del presente y hacer que el pasado perviva? ¿Una teoría que reivindicara los alcances de eso que una vez fue el alma en su constante tensión con una forma? ¿O una teoría que ahora mostrara la imposibilidad del alma o su exilio en el tiempo presente al deshacerse en neurosis e histerias colectivas de una sociedad que fracasaba? ¿O simplemente había que escribir -en la paradoja de escribir por puro desencanto- para evitar el yo a cada palabra?

En el tiempo de la juventud, que en general es místico, eufórico, lleno de esperanzas y por demás desdeñoso para con la felicidad ${ }^{4}$, Lukács, entre los 22 y los 25 años, escribe por lo menos dos obras ejemplares que son epigonales a las ciencias del espíritu: su estudio Historia evolutiva del drama moderno; y los ensayos de El alma y las formas. En ambos libros lo que preocupaba a Lukács era el caos del mundo, la falta de un orden secular, lo que tal vez sea la lenta retirada de una aristocracia de la inteligencia

3 Para un análisis más exhaustivo de las relaciones de Lukács con su tiempo ver el libro de Paul Andrew, The Young Lukács and the Origins of Western Marxism (1979); y el de Giovanni Piana, El joven Lukács (1978).

4 Para un estudio de los aspectos ciertamente interesantes de Lukács en relación a misticismo y juventud recomendamos ver el libro de Michael Lowy, Ideología revolucionaria y mesianismo místico en el joven Lukács (1978). 
que vería su total derrota en el estallido de la primera guerra mundial, la cual, por otro lado, había sido producida por todos los sistemas de representación social de la modernidad en donde esa aristocracia quedó paralizada. Aunque en realidad, más molesto que esas grandilocuentes escenografías del ocaso, lo que perturba al autor de Teoría de la novela es el yo desencantado que ya no es ejemplar como Aquiles o Ayax sino más bien problemático como Hamlet; ya no tiene la atenta escucha de una comunidad sino la soledad de un cuarto propio; ya no habla del mundo porque lo desconoce y entonces habla de sí mismo simplemente para llenar el vacío con palabras. Tras estas contraposiciones, rápidamente podemos ver que lo central en Lukács es un humanismo tardío, una nostalgia del pasado que sólo puede ser redimida con la elaboración de una teoría orientadora que se antepone a toda experiencia del extravío 5 . Es decir entender lo social como resultado de sus disputas y no de sus afecciones. Sin embargo, y he aquí lo que nos importa señalar, ¿cuán lejos está el propio Lukács de todo eso, de ser en algún punto una subjetividad problemática a la cual la atraviesa la incertidumbre del mundo en tanto que experiencia y a la cual la desvela la reserva moral del espíritu en tanto que teoría?, ¿cuán lejos está Lukács de resignar la propia juventud para pasar al destierro del romanticismo anticapitalista pero crítico de ese mismo romanticismo?

\section{La interioridad como contradicción}

Aun cuando el propio Lukács se haya encargado de exponer en sus últimos años que toda su obra -y más aún la de sus primeros años- es una reacción contra el Romanticismo, es imposible no ver en su figura uno de los últimos exponentes de esa forma de pensar lo real a través de posturas irreconciliables y a través de contradicciones. Al respecto Miguel Vedda señala ambas oscilaciones -aceptación y rechazo- en relación a cómo el propio Lukács pensaba el Romanticismo en tanto que problemática propia de una sociología de la literatura, cuando por ejemplo señala en el siguiente pasaje que:

De aquí infiere Lukács una valoración del legado romántico más matizada de la que a menudo se le atribuye; en efecto, sin dejar de cuestionar la nostalgia por el mundo precapitalista presente en buena parte de los artistas y pensadores de dicha tradición, el autor de los Escritos de Moscú reconoce en el Romanticismo una aportación ineludible para el análisis y enjuiciamiento de la Modernidad capitalista ("Realismo y filosofía" 7).

5 Para una reconstrucción de estos primeros años hemos seguido dos textos clásicos que pueden entenderse como biografías intelectuales sobre nuestro autor: Fritz Raddatz, Georg Lukács (1975) y George Lichtheim, Lukács (1972). 
Sin embargo, un apego al Romanticismo, que el propio Lukács comenzaría a relativizar y desmantelar a mediados de 1915, es señalado como imposible de llevar adelante en la compresión de la misma Modernidad por procedimientos que son propios del sentir romántico en relación al presente como problema:

Lukács entiende que una identificación sin reservas con la perspectiva romántica al implicar una postura de unilateral rechazo frente a la Modernidad, tiene que obstaculizar una comprensión de esta en toda su contrariedad; pero también juzga desacertado el empeño de ciertos escritores y pensadores en permanecer anacrónicamente pegados a perspectivas propias del periodo heroico de la burguesía, y en mantener los ojos cerrados frente al hecho de que la realidad posterior a la Revolución Francesa ya no puede ser entendida apropiadamente aplicando los parámetros de la ilustración (8).

La pregunta entonces seria ¿en qué momento Lukács comienza a ver en sí mismo, como una contradicción de procedimiento, el origen de este rechazo del Romanticismo que es por lo pronto una forma de continuidad, crítica y respuesta al desencanto del presente?

Por lo pronto en los años de juventud, el aristócrata de cultura alemana aún cree en una síntesis posible entre la historia y el arte como realización de una esencia a la que llama alma; mientras que al mismo tiempo el incipiente demócrata húngaro vacila ante los espejismos de una conciencia que ni siquiera se reconcilia con las explicaciones que ha podido elaborar del mundo ${ }^{6}$. No basta entonces con escribir en contra del mundo explicando su desacierto en el totalitarismo capitalista al cual éste se ha condenado, sino que también hay que extremar ese carácter de inconformismo y hay que escribir en contra de la propia teoría que critica las formas irredentas de este mundo donde la vida se ha vuelto imposible?

La reacción de Lukács contra el Romanticismo comienza en el propio interrogante que a él lo aquejaba: cómo frente a una serie de singularidades es posible pensar un todo; es decir, cómo es posible que el alma se eleve por encima de lo caótico hacia la forma que la lleva a lo general sin reducción alguna de su esencia. En cierto sentido y en otras palabras cómo es posible conjugar Dostoievski con Kant, el esteticismo con el eticismo. En el ensayo "A propósito de la filosofía romántica de la vida" se señala que en la Alemania de fines de siglo XVIII "nadie podía pensar seriamente una revolución real”, por lo tanto, la respuesta a los tiempos que se avecindaban provenía de

6 Llama la atención que el primer año del Diario se encuentre escrito en alemán, mientras que el año 1911 comienza y termina en húngaro, como si tal diferencia manifestara el proceso de transformación que Lukács lleva adelante desde la publicación de sus primeras obras que varían en lengua, en dedicatorio y en designación sobre sí mismo: George Von Lukács (título nobiliario entregado a su familia por los Habsburgo) / György Lukács (nombre empleado en la segunda edición de El alma y las formas); así como también, las primeras obras y el Diario varían en su finalidad: afirmar un procedimiento sobre el mundo y dudar sobre el mismo ni bien se avizoran los años de crisis.

7 Para ampliar esta doble condición de los primeros escritos de nuestro autor ver el libro de Eva Corredor, György Lukács and the Literary Pretext (1987). 
y se dirigía a "la interioridad" (El alma y las formas 80), esa especie de patria común a todos los espíritus libres de la filosofía, el arte y la política. Planteada entonces una revolución interior, la pregunta romántica, a la cual Lukács no escapa, sino que tal vez reformula para sí mismo, era “¿cómo se puede y se tiene que vivir hoy?” (84), de qué modo es posible pensar un orden, alcanzar un conocimiento del presente que contemple todos sus puntos de tensión. No muy lejos de las aspiraciones más íntimas del Romanticismo la respuesta que Lukács ve en el entusiasmo desmedido de Schlegel y Novalis tiene que ver con que "sólo el culto romántico abarca toda la vida, sólo él no es ninguna renuncia a la vida, ningún apartamiento de su riqueza" (87). Sin embargo, en la no renuncia a la vida, que esconde una brusca superación de toda contraposición, está la debilidad de la Babel espiritual del Romanticismo; su fuerza, el genio como condición de lo humano o la consolidación de una personalidad es precisamente su debilidad cuando no su fe desmedida en lo que Lukács ya juzga como "un individualismo sin compromiso" (89), el cual con el tiempo, suplantará la realidad de la contradicción por una realidad "puramente anímica" perdiendo así "la tremenda tensión que existe entre la poesía y la vida, la tensión que procura a ambas las furazas reales y creadoras de valores" (90). La filosofía romántica de la vida es entonces el culto de la interioridad; pero en un punto también es el triunfo de la muerte como forma última que carece de continuidad alguna al aniquilarse para poder ser realización del yo en el que tanto se confiaba, aún cuando sólo es reducible a un comportamiento trágico: "La tragedia del romanticismo consiste en que solo la vida de Novalis pudo hacerse poesía; su victoria es una sentencia de muerte contra toda la escuela" (95).

Resuelta entonces la filosofía del romanticismo como un alcance solipsista de una realidad anímica que se antepone a las contradicciones del mundo, o también como una posibilidad de vida que se agota en el culto de la personalidad, Lukács cree pertinente revisar la propia vinculación entre teoría y mundo, entre vida y obra para ver hasta qué punto ha sido capaz de desplazar en sí mismo el lastre romántico de su orientación finisecular, pero tal empresa de autocrítica no deja de significarle una tragedia personal como la que observa en sus ensayos en las formas que estudia: "El heroísmo de Kierkegaard consistió en eso: quiso crear formas con la vida. Su sinceridad: vio encrucijadas y recorrió hasta el final el camino por el cual se había decidido. Su tragedia: quiso vivir lo que no se puede vivir" (74). El itinerario de los primeros años de Lukács, ese querer vivir lo que resulta imposible, la estrecha vinculación entre arte y ciencia, entre literatura y vida, está de algún modo fijado en el diario que llevará entre 1910 y 1911, el cual, en cierta medida es una continuidad del horizonte crítico que buscaba desvincularlo del romanticismo, al mismo tiempo que una fuerte crisis de la interioridad que lo impulsaba a concebir la revolución como un aspecto de la interioridad. 


\section{Diario de las contrariedades}

Mejor que en ningún otro caso el Diario escrito entre 1910 y 1911 es una prueba de ese carácter juvenil que se dirime entre la voluptuosidad de las experiencias y la reducción de una teoría a la cual el imperativo de la autenticidad vendría a redimir. Pero, ¿qué se escribe en el transcurso de esos años en un Diario que el mismo Lukács jamás autorizó publicar? A grandes rasgos cada anotación da cuenta de cómo su autor se debate entre el sentimentalismo de la impresión y el deseo del concepto, pues de un lado el sensualismo del mundo se disuelve en la ascesis de la escritura como obra, y del otro lado, la obra naufraga frente a las inclemencias de la vida. Pero a la distancia, estos años de formación no son otra cosa más que tensiones, dudas, renuncias y crisis personales que el objetivismo de la práctica teórica dejará atrás como una imposición resuelta. Así en una síntesis ideal Lukács parece decirnos: si la teoría es el lugar para pensar la literatura, y la literatura está llena de sujetos problemáticos, el diario tiene toda la intensión de ser el lugar adonde lo que se piensa es justamente la teoría; pero la teoría no como forma pura, sino como desencanto puro, como intimidad irreconciliable. Sin embargo, tal reducción resulta imposible, pues la vida misma presenta fenómenos irreconciliables con el pensamiento que ninguna teoría reduce, como por caso el suicidio de una mujer amada -Irma Seidler a quien conoce en 1907 y a quien somete a una cuantiosa correspondencia que nunca define el tipo de relación que Lukács le propone-, o como la muerte inesperada de un amigo -Leo Popper, filósofo y esteta en quien Lukács cifra todas sus esperanzas de ver en él un modelo de filosofía que no lo obligue a pensar en la propia realización. Suicidio y muerte entonces son los elementos íntimos a partir de los cuales Lukács pensara la forma de lo escrito hasta el momento y los resultados que tal procedimiento ha dado para contribuir a acallar el inconformismo y el descontento. Estos dos elementos son también los elementos que superarán la forma de lo escrito, que habilitarán la crisis, la reflexión, la medida del propio alcance y la escritura del yo que se vuelve gigante en su intenso lamento.

Lukács conoce a Irma Seidler el 18 de diciembre de 1907, en ese momento ella tenía 25 años. Entre el 28 de mayo y el 11 de junio de 1908 viajan a Italia y luego mantienen diversos encuentros, hasta que Irma marcha a la Colonia de Pintores de Nagybánya en el sur de Hungría. A partir de ese momento la relación entra en el terreno de una intensa correspondencia donde Lukács nunca define el tipo de relación que podría llega a haber entre ambos. Frente a ésto Irma se casa con un compañero, Károly Réthy, pero el matrimonio no prospera y ella mantiene relaciones con el intelectual y cineasta húngaro Béla Balázs, a quien Lukács, exiliado en Moscú, el 31 de enero de 1940 le escribe: "Te recuerdo el trágico suicidio de Irma, y el papel que tuviste en este acontecimiento". Finalmente, el 18 de mayo de 1911 Irma se suicida y seis días después, Lukács escribe, tal vez reprochándose su comportamiento, "no podré ser nunca nada para nadie, y si acaso alguien pudiera todavía significar algo 
para mi haría bien en huir porque soy un leproso y podría contaminarlo". En 1913 redacta un diálogo titulado El Juicio, en el que dos amigos se reúnen para hablar sobre el suicidio de una tercera. Bajo el nombre de Erwin se esconde Lukács y bajo el de Paul Béla. A su vez este hecho tiene una segunda versión escrita en un esbozo de novela titulado Leyenda del rey Midas. El 21 de octubre de 1911 muere de tuberculosis Leo Popper, filósofo y esteta en el que Lukács cifra todas sus esperanzas de ver un modelo de filosofía. Esto lleva a que en su Diario Lukács pase de escribir en húngaro a hacerlo en alemán y registre entradas como la siguiente: "No sé por que empiezo otra vez a escribir. ¿Es esto un comienzo o acaso el fin? Sería vano hablar al respecto. Ayer murió Leo. Ahora todo es distinto. Me encuentro otra vez arrojado hacia mí mismo. Alrededor mío sólo la noche y el vacío" $(76)^{8}$.

De este modo el joven Lukács que ha reducido lo caótico a formas más que transparentes para el alma, que ha escrito dos libros ejemplares, que se obstina en trabajar a jornada completa para justificar su existencia mientras viaja por Europa huyendo de la decadencia que se ha apoderado de todo el continente, comprueba que en verdad el único lugar donde es ciertamente auténtico es el lugar donde más se deja ganar por lo caótico que tanto teme. En la escritura del diario que da cuenta de los pormenores de un intelectual que duda sobre el método que ha seguido y que tiene que seguir, está definitivamente la vida como algo perdido en la paradoja trágica de quien se entrega a la obra para perder definitivamente una mujer, un amigo, la inteligencia misma del amor. A lo cual, la pregunta que lacera la interioridad, y que pone en crisis todo lo pensado hasta ahora, es ¿alcanza la forma a contener lo irreductible de la vida, ya sea esto el suicidio de una mujer amada o la muerte de un joven amigo?

Frente a la seguridad de la teoría que en cada libro de Lukács avanza entre conceptos que una y otra vez se definen cuando no se reducen a metáforas de clara oscuridad, el Diario - ese registro menor, ese opúsculo olvidado por el propio autoraparece como el sendero en el cual las palabras transitan la angustiante opacidad de la tragedia personal. Así sin resolver un posible compromiso sentimental, privado de la seguridad de un convencimiento trascendente en los alcances de la razón, y además entregado a la suerte de un reducido círculo de intereses y nombres amistosos en los cuales desentenderse de él mismo, Lukács enfrenta en cada página de esos años la tan temida interioridad que rechazara en sus libros anteriores. Anotaciones como: "Esta noche he vuelto a sentirlo: Irma es la vida" (77), o mucho más puntuales: "Ahora siento de nuevo como una flaqueza haber "acabado" con Irma en Pest" (82), cuando no anotaciones que significan un retroceso del concepto ante el puro sentimiento: "De esta manera toda esa abstracta metafísica de la forma nos vuelve a llevar al centro

8 Para mayores precisiones ver el artículo de Ágnes Heller, “György Lukács e Irma Seidler" en Apuntes para la historia de la ética (1973). 
de todas las cosas: a Irma" (89) llaman la atención sobre la evidente contraposición entre teoría y vida. Es así que en el Diario vemos que el problema entre teoría y vida es su no reducción a una síntesis, su carácter irrenunciable a la inmanencia que las constituye y las hace ser tales polos opuestos: por un lado la vida es necesariamente renuncia, por el otro la teoría es afirmación esperanzada. Problema que en los ensayos de El alma y las formas no se enuncia y se da como superado, trascendido por la propia escritura, resuelto en la forma acabada del libro: el ensayo que puede conjugar ciencia y arte, que puede tomar para sí literatura y vida sin reducción alguna en su palabra acertada y su imprecisión general. Sin embargo el Diario también nos dice lo contrario, pues la intención de Lukács era -al menos en los primeros escritos que van de 1908 a 1910 - erradicar tal contraposición hasta hacer que la teoría emane de la vida, como lo demuestra en la siguiente queja: "Creo que resulta apenas perceptible -ni siquiera para Leo- que el carácter radical del ensayo sobre Ernst es el de un ensayo sobre Irma" (98). De este modo el ascetismo de Lukács -que no es nada nuevo, pues comienza en Flaubert y llega a su punto máximo en Kafka, y consiste básicamente en hacer de la teoría el todo que está faltando a la vida- en algún punto fracasa en una metáfora desolada: “ ¿podrá el calor de mi productividad resistir este desierto de hielo?” (103). El suicidio de la amada, la muerte del amigo, la desaparición de lo que fuera el origen de cada escrito entusiasta no encuentra lugar ni siquiera en el consuelo de la obra, pues el propio Lukács se dice y se maldice al escribir: "Me parece que estoy siendo castigado por mi arrogante soberbia, por mi confianza en la obra y en el trabajo invertido en ella" (108).

Por medio de la obra Lukács cree entonces poder erradicar el desencanto, es más, quién no pudo aspirar a la literatura se consuela con la filosofía: "Todo conduce a la vieja pregunta ¿cómo puedo ser un filósofo?” (123). Pero en realidad, la renuncia al desencanto que lo hace escribir una y otra vez sobre él, la aspiración a lo sustancial que una y otra vez lo anima, tiene su origen en la falla del método, en el reconocimiento de la reducción que paraliza: “Todo en mí alcanza una dimensión dialéctica. En mi vida no puede entrar ningún elemento de realidad, no puedo tomar una decisión" (115). Como si la vida fuera un contraste rotundo Lukács alcanza a confesarse en el último momento de quien se arrepiente de sus pecados: "vivo en un retraimiento frívolo, concentrándome en problemas exclusivamente intelectuales" (110), los cuales por más ascéticos que parezcan, concluyen en la desesperación a la cual se le busca absolución alguna: "La inteligencia me ha arruinado; durante demasiado tiempo y de una manera demasiado exclusiva la realidad puramente intelectual, la embriaguez del trabajo llegaron a sustituirlo todo" (118).

Sin embargo el lento abandono del desencanto y la aceptación de un sistema de pensamiento que modifique desde lo real y sus relaciones estructurales la configuración del mundo que nos rodea, se lleva por delante no sólo la intimidad del mismo Lukács, que abandonará toda escritura del yo y jamás dejará saber nada sobre ella, sino también toda la configuración de un sistema de ideas. Del impresionismo ensayístico 
al rigor de la sociología hay un transito por demás interesante: Lukács abandona la literatura como experiencia, y la transforma en un objeto puro de la intelección entre condicionantes históricos y subjetividad. Es decir, erradica el factor vital que creía ver en ella como irreductible. Así en un diario que por más de 40 años permaneció a la sombra de edición alguna, concluye el sueño de todo idealismo crítico: "Lo desesperanzador de mi teoría de las categorías tiene que estar más allá de antítesis como felicidad-infelicidad, optimismo-pesimismo, etc. Y tampoco tiene que ser trágica; a pesar de que, en mi opinión, el fenómeno básico de lo trágico se sitúa más allá de estos conceptos" (110).

Del mismo modo entonces en que lo íntimo carece de forma, la aventura espiritual de Lukács de pensar el mundo en categorías que erradiquen la continuidad romántica del yo carece de alcance alguno, pues lo trágico es que tal erradicación es parte de un más allá de la voluntad adonde no se puede acceder salvo a través de la intimidad. Parecería ser entonces que el aprendizaje de esto años consiste en que frente al problema de la siempre presente filosofía romántica como procedimiento de las relaciones entre sujeto y objeto, y la interioridad como un problema propio de quien escribe y percibe el mundo, es mejor callar, abandonar cualquier propósito, guardar la valoración subjetiva que lo hace a uno no divisar la objetividad necesaria para tratar tal tema. En su estudio sobre la correspondencia de Regina Olsen y Kierkegaard -otro filósofo que interrumpe todo compromiso y abrasa la escrituraLukács ya había sido lapidario al señalar "No hay ningún sistema para la vida. En la vida existe sólo lo singular, lo concreto. Existir significa ser diferente" (El alma y las formas. Teoría de la novela 62), sin embargo esa diferencia -que es la que aparece en el Diario - aterroriza y debilita, es digna de olvidar bajo el peso aplastante de una ontología del ser social donde el yo esté sepultado bajo una ética materialista que borre todo lastre de decadencia finisecular, pues más allá de la juventud el yo habla por última vez y sugiere: "cerremos el diario: el tiempo de los sentimientos ha concluido [...] ha sido mi época más endeble y haber escrito un diario fue siempre señal de debilidad" (Diario 123).

\section{La renuncia como forma de afirmación}

Para concluir podríamos señalar que paradójicamente el diario como escritura de debilidad es una escritura que socava todo cimiento de lo escrito. Lo seguro, lo propio, lo que se capitaliza como logro ante los ojos del día a día de la aceptación, en la noche de la escritura del diario como puesta en duda se vuelve incierto, endeble, falso y hasta totalmente ajeno al deseo de escritura. Por momentos la escritura del diario es una suerte de prueba de la autenticidad, un registro de los lugares a los cuales la forma ha conducido al espíritu y un auto de fe del convencimiento que el espíritu ha alcanzado en ese lugar al cual ha llegado. La presunta autenticidad del diario tiene que 
ver entonces con el nivel de intensidad con el cual el sujeto de la escritura enuncia los horizontes a los que aspira llegar como tal, más allá de si es un crítico o un escritor.

Sin embargo las vacilaciones de Lukács sobre si la reflexión y la crítica en literatura deben ser pensadas como ciencia o como arte, ya se encuentran presentes en lo escrito para el gran público y vinculan así lo público y lo privado; El alma y las formas contiene elementos propios de esta puesta a prueba del desencanto. En carta a Leo Popper, reflexionando sobre la forma del ensayo, la argumentación lukácsiana hace evidente su temor más íntimo al interrogar al amigo sobre los alcances de una forma que es pensada también como un método:

en qué medida el tipo de intuición y su configuración excluyen la obra del campo de las ciencias y la ponen junto al arte pero sin borrar el límite entre ambos; en qué medida le comunican la capacidad de una nueva reordenación conceptual de la vida, manteniéndola al mismo tempo, lejos de la perfección helada y definitiva de la filosofía (15).

Contemporánea al Diario -la fecha de escritura de la carta-prólogo es Florencia, octubre de 1910 - esta apelación al filósofo amigo abre la puerta a pensar la contaminación propia que existe entre lo privado y lo público cuando cualquier proyecto intelectual se deja ganar por cierto vitalismo propio de la edad temprana; es más, en cierto sentido permite afirmar que la intimidad como forma de escritura del yo se posiciona también en los textos presuntamente no relativos a la intimidad, pues la carta hace las veces de prólogo a los tempranos ensayos de Lukács, y así, lo íntimo, emerge aquí y allá como rémora de aquello que no se sabe cómo orientar. Por lo cual, si el diario era el lugar adonde la teoría se sometía a la posibilidad de la duda y el desencanto; en el ensayo mismo que presume de hacer teoría, de querer otorgar una forma al mundo del alma, la duda es fundante de esta posibilidad; de ahí entonces que Lukács tema el irracionalismo que tienta al desencanto.

De este modo el Diario va mucho más lejos de la presunta tarea de anotación y registro, pues éste se transforma en un momento en una forma de pasión, no por la escritura justamente, sino en el sentido de expiación, de vuelta sobre el método, de vista que mira atrás, al camino recorrido en la fabulación de todo ascenso, y levanta los ojos hacia el cielo teórico que deseó midiendo la distancia que ha cumplido y aún lo separa. Que Lukács renuncie a toda proximidad con su objeto de estudio, ya sea en la interpretación del mismo sin mediación alguna más que aquella que puede significar el ejercicio del estilo, y que asuma una tratativa del método por medio de los aportes de las lecturas de Hegel primero y luego de Marx ${ }^{9}$, evidencia cierto pasaje desde el ensayismo individual del descontento a una sociología de la historia como singularidad sin sujeto.

9 Dichas lecturas serán respectivamente dos libros centrales de Lukács: Teoría de la novela (1920) e Historia y conciencia de clase (1923). 
En su función entonces de ato-percepción sobre lo escrito, el Diario permite radicalizar la teoría, pues al enjuiciar al yo disconforme no hace otra cosa más que prepara la clausura de la intimidad, a la vez que permitiría una orientación analítica hacia la ontología de lo social en una sociología de las ideas. La juventud perdida es entonces la renuncia al irracionalismo del espíritu que presume de ser puro empeño, método sin orientación más allá de si mismo; mientras que la madurez ganada no es otra cosa más que aplicación rigurosa de las ideas de Hegel y Marx como superación justamente de todo individualismo que pretenda anteponerse a la realidad y reducirla a su singular padecimiento. De este modo, podemos concluir que Lukács pensando el límite de lo romántico y padeciendo el propio alcance de lo romántico, entrevió en su forma más singular como lo es el diario, la necesidad que lo llevó a superar tal instancia del espíritu; pero para ello, debió renunciar a esa singularidad que había sido el origen de toda escritura: el desencanto del yo.

\section{Referencias}

Andrew, Paul. The Young Lukacs and the Origins of Western Marxism. New York: Seabury Press, 1979. Medio impreso.

Arfuch, Leonor. El espacio biográfico. Dilemas de la subjetividad contemporánea. Buenos Aires: Fondo de Cultura Económica, 2002. Medio impreso.

Catelli, Nora. El espacio autobiográfico. Barcelona: Lumen, 1991. Medio impreso.

---. En la era de la intimidad. Rosario: Beatriz Viterbo Editora, 2007. Medio impreso.

Corredor, Eva. György Lukács and the Literary Pretext. New York: P. Lang, 1987. Medio impreso.

Eakin, Paul. How lives become stories. Makin Selves. Cornell: University Press, 1999. Medio impreso.

Giordano, Alberto. El giro autobiográfico de la literatura argentina actual. Buenos Aires: Mansalva, 2008. Medio impreso.

Heller, Ágnes. "György Lukács e Irma Seidler". Apuntes para la historia de la ética. Budapest: Gondolat, 1973. 57-78. Medio impreso.

Lichtheim, George. Lukács. México: Grijalbo, 1972. Medio impreso.

Link, Daniel. "La imaginación intimista”. http://linkillo.blogspot.com.ar/2007/08/ la-imaginacin-intimista.html. Fecha de ingreso: 9 de agosto de 2014. Sitio web.

Lowy, Michael. "Ideología revolucionaria y mesianismo místico en el joven Lukács". El marxismo olvidado: 37-55. Barcelona: Fontamara, 1978. Medio impreso.

Lúkacs, György. Diario 1910-1911 y otros escritos de juventud. Trad. Páter János Brachfeld. Barcelona: Ediciones Península, 1985. Medio impreso.

---. El alma y las formas. Teoría de la novela. Trad. Manuel Sacristán. México: Grijalbo, 1985. Medio impreso. 
---. Escritos de Moscú. Estudios sobre política y literatura. "Realismo y filosofía. Los debates del Lúkacs maduro contra la sociología vulgar”, Buenos Aires: Editorial Gorla, 2011. Medio impreso.

Piana, Giovanni y otros. El joven Lukács. México: Cuadernos de Pasado y Presente, Siglo XXI, 1978. Medio impreso.

Raddatz, Fritz. Georg Lukács. Madrid: Alianza editorial, 1975. Medio impreso.

Sibilia, Paula. La intimidad como espectáculo. Buenos Aires: Fondo de Cultura Económica, 2008. Medio impreso.

VV.AA. "Escrituras del Yo". Badebec 1 (septiembre 2011). http://www.badebec.org/ badebec_1/sitio/index.php. Fecha de ingreso: 9 de agosto de 2014. Sitio web.

Recibido: 15 agosto 2014

Aceptado: 17 marzo 2015 